\title{
Physical activity of middle-age adults aged 50-65 years in view of health recommendations
}

\author{
Wladyslaw Mynarski • Michał Rozpara • Agnieszka Nawrocka • \\ Zbigniew Borek • Aneta Powerska • Wieslaw Garbaciak
}

Received: 16 May 2013 / Accepted: 14 January 2014 / Published online: 28 January 2014

(C) European Group for Research into Elderly and Physical Activity (EGREPA) 2014

\begin{abstract}
The objective of the study was to assess the level of habitual physical activity, mainly its frequency and duration, of middle-age adults aged 50-65 years in a typical week of their life in comparison to the level of these parameters recommended for health benefits. The study carried out in the Upper Silesia region in Poland in May 2010 included 456 deliberately selected subjects ( 234 women and 222 men) aged $50-65$ years. Numeric data were collected by diagnostic survey method using the short version of IPAQ. The surveyed men were characterized by higher level of physical activity than the surveyed women (longer duration and higher frequency)
\end{abstract}

Declaration of original research The authors declare that the manuscript entitled "Physical activity of middle-age adults aged 50-65 years in view of health recommendations" has not been published elsewhere, accepted for publication elsewhere, or under editorial review for publication elsewhere.

Authors' contribution Władysław Mynarski-study design, data collection, and manuscript preparation

Michał Rozpara - study design, data collection, and statistical analysis and interpretation

Agnieszka Nawrocka - data collection and manuscript preparation

Zbigniew Borek - study design and data collection

Aneta Powerska - data collection

Wiesław Garbaciak - data collection

W. Mynarski $\cdot$ M. Rozpara $\cdot$ A. Nawrocka $\cdot$ A. Powerska

Department of Recreation, The Jerzy Kukuczka Academy of

Physical Education in Katowice, Katowice, Poland

Z. Borek

Department of Tourism, Cracow University of Economics, Cracow, Poland

W. Garbaciak

Department of Theory and Methodology of Physical Education, The Jerzy Kukuczka Academy of Physical Education in Katowice,

Katowice, Poland

Z. Borek $(\bowtie)$

ul. Krótka 18, 41-806 Zabrze, Poland

e-mail: z.borek@poczta.onet.pl $(p<0.01)$. This regularity was observed both for moderateand vigorous-intensity physical activity. At the same time, significantly higher percentage of men (41\%) than women (28\%) met the recommendations of the American College of Sports Medicine (ACSM) on physical activity beneficial for health $(p<0.01)$. The level of physical activity of the surveyed group of older adults was estimated as unsatisfactory $-72 \%$ of women and $59 \%$ of men did not perform physical activity resulting in the expected health benefits.

Keywords Physical activity · Assessment · Middle-age · IPAQ $\cdot$ Recommendations

\section{Introduction}

In view of scientific information confirmed repeatedly, insufficiency of physical activity becomes the cause of epidemics of serious diseases in contemporary generations, of cardiovascular, respiratory, and musculoskeletal systems as well as neoplasms and metabolic diseases. These diseases are the main cause of premature deaths, particularly among adults aged 50-65 [5, 7, 12, 17, 29, 33]. Therefore, promoting physical activity becomes an obligation for institutions and organizations responsible for public health. Programs of actions in this field should be based on the results of thorough diagnosis and assessment of physical activity level (PAL) in particularly threatened social groups, including adults aged $50-65$.

Energy expenditure is the best indicator of physical activity. However, its completely objective measurement is possible only in laboratory conditions $[15,19]$. In epidemiological studies, the most frequently used method of assessing the level of physical activity is diagnostic survey, while the research tools are questionnaires. This method is also the most practical 
in the diagnosis of physical activity of middle-age adults [18, $20,21]$.

One of the world's most frequently used tools of a diagnostic survey of physical activity is the international physical activity questionnaire (IPAQ). Its advantages are as follows: simple and unified research procedures and short time of its completion. It allows to gain information on the frequency and duration physical activity accompanying habitual activity of subjects at three levels of intensity (low, moderate, and vigorous) [14]. Numerous international studies have proved satisfactory diagnostic reliability of IPAQ in comparison to the measurement of energy expenditure during physical activity $[3,6,27]$ as well as in monitoring of physical activity of middle-age adults $[2,18,20]$.

Respondents' answers to questions included in IPAQ, concerning the frequency and duration of moderate- and vigorous-intensity physical activity (MVPA) performed weekly, allow to assess subjects' physical activity in comparison to the level of physical activity beneficial for health, recommended by world organizations and research centers $[11,13$, $14,26,32]$. It is one of the significant trends in the studies of physical activity of middle-age adults (with or without health disorders) $[6,32]$. This issue has been rarely the subject of studies carried out by Polish researchers [2, 24].

\section{Aim of the study}

The aim of the study was to assess the habitual physical activity of individuals aged 50-65 years in a typical week of their lives in comparison to the norms of physical exercise recommended for health benefits by the American College of Sports Medicine (ACSM) [11, 14]. We also tried to answer the question to what extent gender, age, education, and BMI of the subjects determine in fulfilling the above mentioned recommendations.

\section{Material and methods}

The study included 456 individuals (234 women and 222 men) living in the Katowice agglomeration. The material of the study were family members and close acquaintances of interviewers, who had basic knowledge on the respondents' life style, character of their work as well as leisure-time (recreational) activities. The purposeful selection of the study group assumedly was to support the verification of the truthiness of the respondents' answers, since all the data collection was carried out in the presence of a respondent. The interviewers were the third year students of the Academy of Physical Education in Katowice, Poland, who had personal experience in assessing the intensity of physical activity.
Physical activity of the subjects was assessed using the short version of IPAQ. It includes seven questions concerning their physical activity in a typical week of their life. The subjects' answers concerning the self-reported frequency and duration of physical activity in two areas of intensity, namely vigorous (PA1) and moderate (PA2) were used in statistical analyses. The data were confronted with the levels of physical activity recommended by ACMS experts for adults aged 1865 years in the form of two equivalent criteria:

- Three times a week, vigorous-intensity physical activity of at least 20 min duration

- Five times a week, moderate-intensity physical activity of at least 30 min duration [11].

The subjects fulfilling at least one of the above mentioned criteria were classified as complying to the ACSM recommendations, while the remaining respondents, as physically active below the health benefit level. In the first step of statistical analyses, the percentage of these two categories of subjects among women and men was calculated, and then additionally, the percentages of subjects fulfilling and not fulfilling the above mentioned criteria according to their age, education, and BMI were determined.

Three age categories of the surveyed men and women were specified-50-54, 55-59, and 60-65 years; three levels of education - vocational (nonacademic level of education in Poland that prepares pupils for specific trades and crafts, usually based on manual or practical activities), secondary, and higher; and three categories of somatic build, based on BMI-normal $\left(\mathrm{BMI} \leq 24.9 \mathrm{~kg} / \mathrm{m}^{2}\right)$, overweight $(\mathrm{BMI}=25.0$ $\left.29.9 \mathrm{~kg} / \mathrm{m}^{2}\right)$, and obese $\left(\right.$ BMI $\left.>29.9 \mathrm{~kg} / \mathrm{m}^{2}\right)$.

Arithmetic means $(\overline{\mathrm{x}})$, standard deviations (s) as well as minimal (Min) and maximal (Max) values were calculated for the examined variables. The differentiation of the results of women and men was assessed using the Mann-Whitney $U$ test. The level of fulfilling the ACSM recommendations for physical activity beneficial for health according to the gender of the subjects was verified using Pearson's chi-squared test for independence. Statistical inference was conducted at the probability level of $p<0.05$ assumed ex ante. The calculations were carried out using the Statistica software of the StatSoft company.

\section{Results}

The study indicated significant differences $(p<0.001)$, in favor of men, of the average values of parameters characterizing the somatic build of the subjects aged 50-65 (Table 1). Maximal values of BMI point out that the surveyed group included overweight and obese individuals. 
Table 1 Numerical characteristics of variables describing the somatic build of the surveyed women and men

\begin{tabular}{llllllll}
\hline Variables & Gender & $\bar{x}$ & $\mathrm{~s}$ & Min & Max & $U$ & $p<$ \\
\hline Height $[\mathrm{cm}]$ & Women & 164.8 & 6.5 & 149.0 & 190.0 & 4970 & 0.001 \\
& Men & 176.8 & 6.8 & 160.0 & 193.0 & & \\
Weight $[\mathrm{kg}]$ & Women & 66.9 & 10.6 & 46.0 & 100.0 & 7430 & 0.001 \\
& Men & 82.9 & 10.9 & 55.0 & 130.0 & & \\
BMI $\left[\mathrm{kg} / \mathrm{m}^{2}\right]$ & Women & 24.7 & 3.6 & 17.6 & 36.7 & 17782 & 0.001 \\
& Men & 26.5 & 3.1 & 18.7 & 39.2 & & \\
\hline
\end{tabular}

The average frequency of vigorous- and moderate-intensity physical activity of the surveyed women and men was lower than recommended by the ACSM for health benefits, while vigorous-intensity physical activity was significantly more frequent among men than among women $(p<0.01)$. The frequency of moderate-intensity physical activity was similar in both genders (Fig. 1).

The average duration of physical activity at the two examined levels of its intensity was significantly longer than the values assumed by the ACSM experts as minimal for health benefits, both among women and men, and the average duration of physical activity in the group of men was significantly higher than in the group of women ( $p<0.01)$ (Fig. 2).

Low frequency of physical activity of vigorous and moderate intensity taken up by women and men in a week, indicated in the study, resulted in the low percentage of the respondents whose habitual physical activity could be assessed as beneficial for health in light of the ACMS recommendations. Only $28 \%$ of the surveyed women and $41 \%$ of men fulfilled at least one of the two criteria of physical activity beneficial for health mentioned earlier. The remaining respondents declared physical activity below these criteria. The difference in favour of men was statistically significant $\left(\chi^{2}=\right.$ 7.70, $p<0.01$ ) (Fig. 3).

During further analyses, we tried to determine the above described differences in the percentage of subjects fulfilling

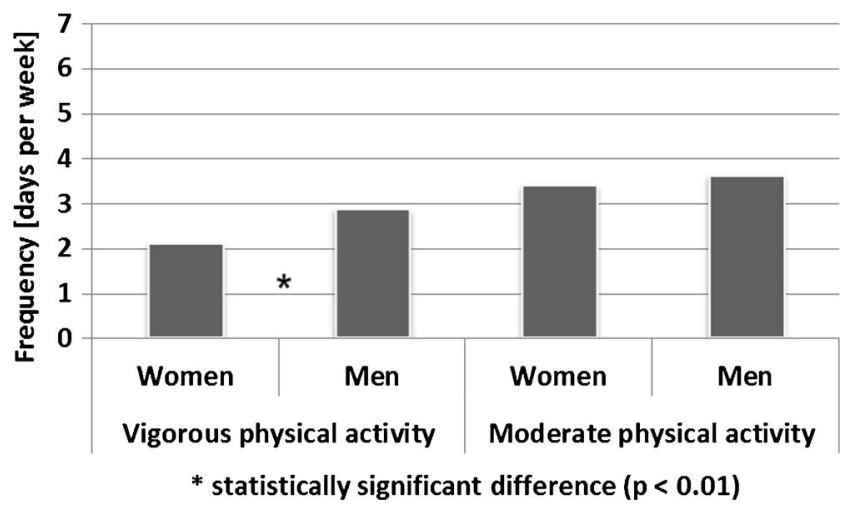

Fig. 1 The frequency of vigorous-intensity (PA1) and moderate-intensity (PA2) physical activity in women and men

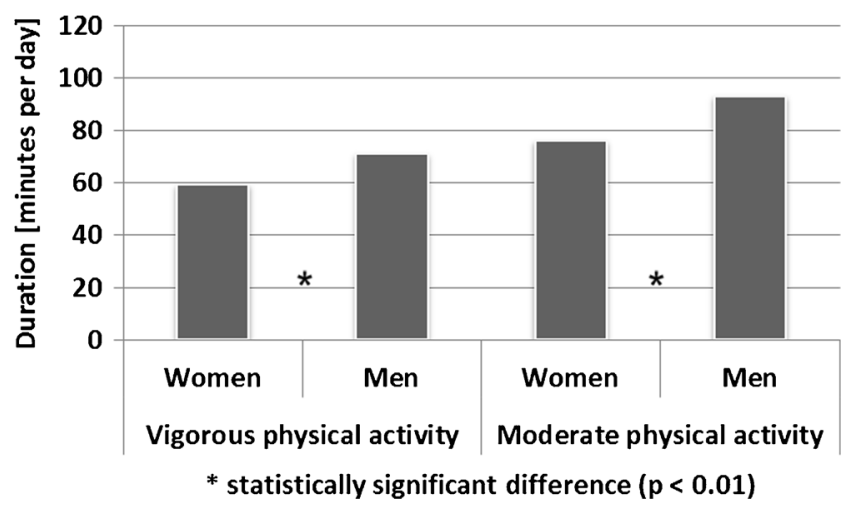

Fig. 2 The duration of vigorous-intensity (PA1) and moderate-intensity (PA2) physical activity in women and men

the ACSM recommendations taking into account also age, education, and BMI of the surveyed women and men.

In the two categories, first of the specified age categories, i.e., 50-54 years and 55-59 years, men significantly more frequently than women fulfilled the criteria of physical activity beneficial for health (respectively $\chi^{2}=5.45$ and $\chi^{2}=4.29$; $p<0.05$ ). In the second, the $60-65$ age category, the percentage of men fulfilling the above mentioned criteria was significantly lower and approximately the same as the percentage of women (Fig. 4).

The division of the subjects according to the level of education reveals similar trends. Men with vocational and secondary education significantly more frequently met the criteria of physical activity for health benefits recommended by the ACSM as compared with women (respectively $\chi^{2}=$ 6.56 and $\chi^{2}=5.61 ; p<0.05$ ). The percentage of the surveyed men and women with higher education declaring health activity of the parameters recommended by the ACSM for the desired health benefits was almost identical and relatively low (respectively $27 \%$ and $28 \%$ ) (Fig. 5).

The percentage of men fulfilling the ACSM physical activity recommendations was significantly higher in comparison with the percentage of women only in the group including

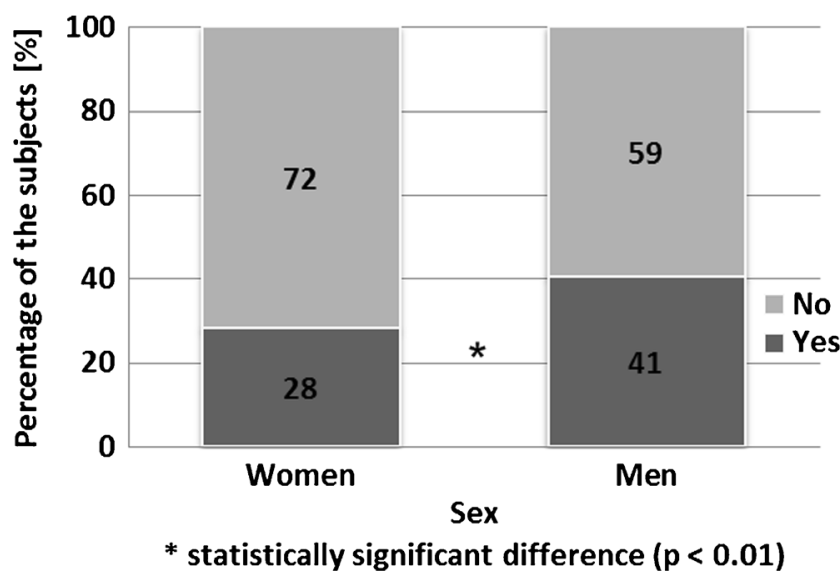

Fig. 3 Percentage of women and men fulfilling the ACSM recommendations on physical activity beneficial for health 


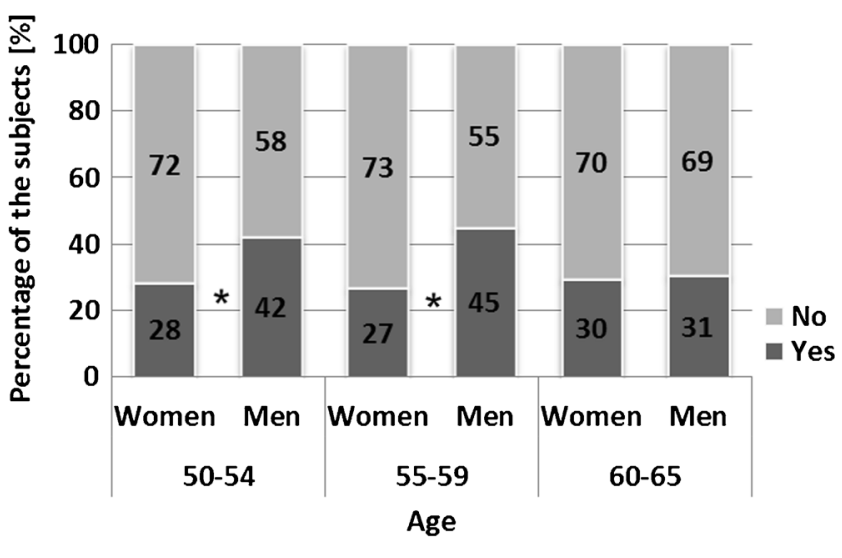

* statistically significant difference $(p<0.05)$

Fig. 4 Percentage of women and men fulfilling the ACSM recommendations on physical activity beneficial for health according to age

subjects of normal body weight $\left(\chi^{2}=4.44, p<0.05\right)$. Similar relations (the prevalence of men over women) were also demonstrated in overweight and obese respondents; however, the differences were statistically insignificant (Fig. 6).

\section{Discussion}

The aim of the study was to assess physical activity of women and men aged 50-65 years in view of health recommendations. Regular physical activity performed in everyday life and in leisure time, among others, is validated nowadays as bringing health benefits. Therefore, to assess habitual physical activity of the subjects, we used the short version of IPAQ, in which the participants declared their performance of all physical activities of at least 10 min duration. Only $28 \%$ of all surveyed women and $41 \%$ men performed, throughout their typical week, physical activity recommended by the ACSM as standards in order to gain health benefits. These

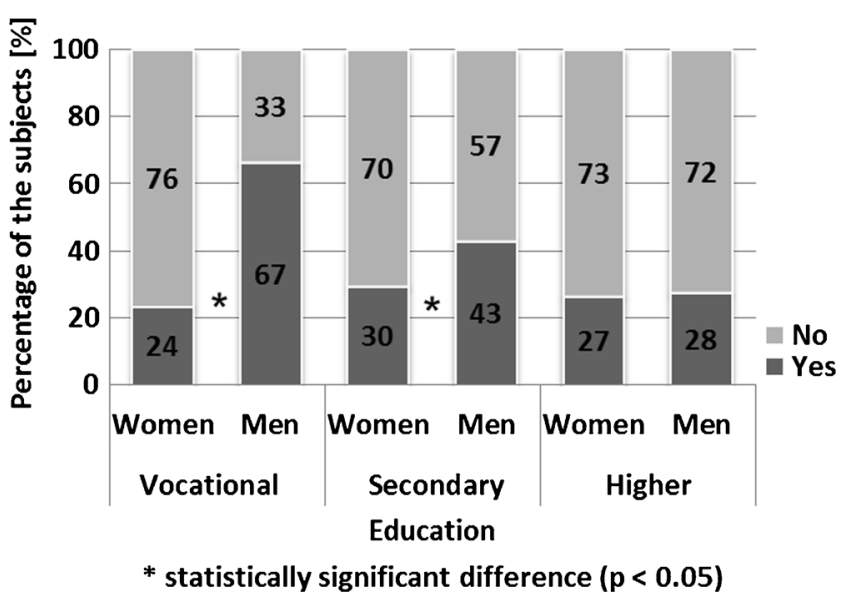

Fig. 5 Percentage of women and men fulfilling the ACSM recommendations on physical activity beneficial for health according to the respondents' education

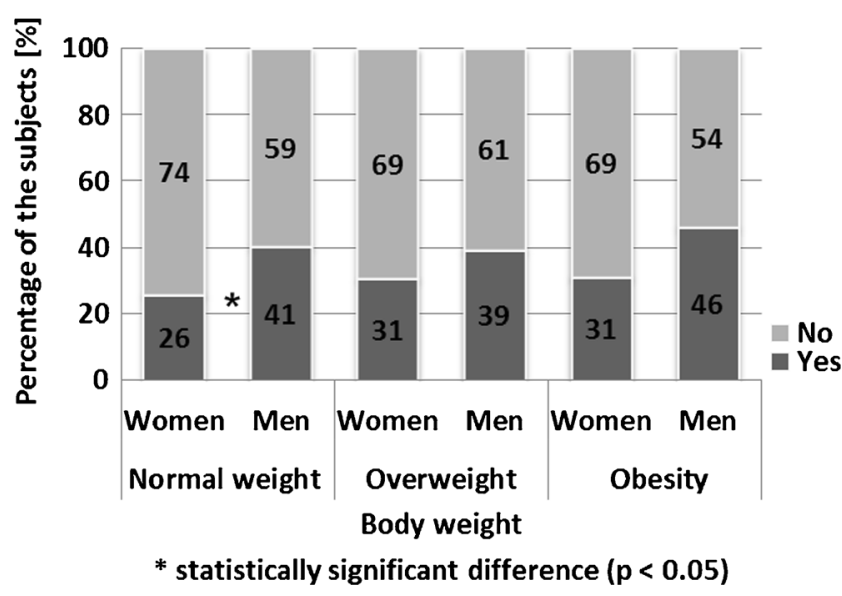

Fig. 6 Percentage of women and men fulfilling the ACSM recommendations on physical activity beneficial for health according to their body weight

recommendations are regarded as the most up-to-date and well-founded scientifically [11]. The ACSM recommendations include three main criteria of physical activity for health benefits: frequency per week, intensity, and duration per day [14].

Our research showed that the majority of the surveyed women and men did not meet the criterion of the frequency of vigorous- and moderate-intensity physical activity. Only physical activity of such frequency is regarded nowadays as benefiting for health $[11,14,26]$. The average frequency of vigorous-intensity physical activity of the female and male subjects was two times per week, while of moderate-intensity physical activity, three times per week. The ACSM recommendations set these levels at three and five times (respectively) per week [14].

However, the vast majority of the participants of both genders did meet the criteria of total duration of habitual physical activity per day on days when it was performed. It was respectively $60 \mathrm{~min}$ among women and $70 \mathrm{~min}$ among men for vigorous-intensity physical activity and $75 \mathrm{~min}$ among women and $90 \mathrm{~min}$ among men for moderateintensity physical activity throughout the day. It exceeded the recommended levels (20 min of vigorous-intensity physical activity and 30 min of moderate-intensity physical activity) more than two times. Therefore, the reason for not meeting the standards of physical activity for health benefits was mainly its low frequency per week. This is the main finding of our research. It should be emphasized here that the parameters of physical activity for health benefits recommended by the ACSM are regarded as the minimum. Everyday, physical activity of at least moderate intensity is more and more frequently pointed out as the model of physical activity for health benefits [11].

Our research showed statistically significant differences of the percentage of the surveyed females and males meeting the ACSM recommendations in some of the selected subgroups, 
depending on age, education, and BMI of the participants. The prevalence of young individuals over older adults, as well male gender over female, in fulfilling the basic parameters of habitual physical activity was proved by several researchers $[22,28,30]$. Our research confirmed this trend also among older adults aged $50-65$ years.

Other studies indicate that higher level of physical activity generally characterizes individuals with normal BMI [1, 3, 16, $31]$ and that habitual physical activity increases with the increase of the education level [25]. In our study, only the percentage of men with the normal BMI meeting the ACSM criteria was significantly higher than among women. We also demonstrated that men with vocational education outnumbered women over two times in meeting the criteria of physical activity for health benefits recommended by the ACSM. Only in this case, men who fulfilled the ACSM recommendations prevailed over those who did not fulfill them. The probable cause was the physical effort of these men during their occupational activities, associated with their qualifications (level of education).

As far as other criteria are concerned, both in female and male subgroups, the number of subjects that met the ACSM recommendations was significantly lower than those who did not meet them. The reason was certainly the fact that the majority of the surveyed men worked in professions requiring physical effort. Such individuals were the minority among women. It may be concluded that occupational physical activity was the factor that determined higher percentage of men fulfilling health recommendations. At the same time, it indicates low percentage of male individuals performing leisuretime physical activity. Similar conclusion was drawn by Biernat [2] for the representatives of the population of Warsaw of both genders.

In summary, physical activity recommended for health benefits was performed more frequently by men of normal BMI, with vocational and secondary education, and aged 5060 years. The percentage of such individuals was only about $40 \%$. Similar trends were observed in female subgroups to a lesser extent.

In view of the purposeful selection of the study group, according to the criteria characterized in the section Material and methods, this conclusion may be interpreted only as (statistical) trends observed in the group of men and women studied by us. The aim of the author's papers is to carry out a similar study in a randomly selected sample of five million population of the Silesian agglomeration (Upper Silesia, Poland).

Insufficient physical activity at the level bringing health benefits and its negative consequences in older adults has already been documented in numerous world studies. Their findings are consistent with our study $[1,4,5]$.

The study carried out in Brazil, within the program Behavioral Risk Factor Surveillance System (BERFS), indicated that at the beginning of the twenty-first century, $60 \%$ of healthy individuals and $70 \%$ of those with health disorders did not perform the sufficient amount of physical activity. Leisuretime physical activity, as well as connected with occupation and daily chores, was assessed, similar to our study (IPAQ).

Observations carried out in Switzerland among individuals aged " $50+$ " proved that $9 \%$ of subjects was physically active at the moderate level, while $18.2 \%$, at the vigorous level. Among the remaining subjects, $8.7 \%$ was assessed as active at the optimal level, whereas $47 \%$ performed only physical activity connected with daily chores [23].

The diagnosis of the physical activity of the population of European countries (Bridging Earth, Worth Gap Project) pointed out that only 6-8\% of the population of Poland may be classified as physically active at the vigorous level [8]. The health assessment of Poles indicated physical activity of $50-60 \%$ of subjects as too low; this applies particularly to individuals aged 50 years and older [9].

Numerous studies emphasized higher level of physical activity among individuals with higher education; however, it concerned generally leisure-time physical activity $[1,19]$. At the same time, it was indicated that over $50 \%$ of individuals aged 60 years and older did not perform recommended physical activity [19]. We derived similar conclusion based on our study.

Numerous papers point out that normal build of older adults, particularly normal body weight, favors higher level of physical activity [1, 3, 10, 31]. In our study, normal weight men significantly more frequently complied with the ACSM recommendations as compared to those who were not physically active enough. Similar relationship was not observed among women, probably because the majority of them displayed a low level of physical activity.

The findings of longitudinal studies of mortality among individuals displaying high and low levels of physical activity are of particular interest. They proved, among others, that after 15 years of increased physical activity, the risk of premature death significantly decreased in men aged 50 years as compared to individuals who did not increase their level of physical activity [5]. Therefore, the conclusions of the majority of papers on physical activity of individuals aged 50 years and older emphasize its undisputed significance for the health and well-being of contemporary generations. The efficient promoting of properly dosed physical activity, particularly among older adults, is therefore considered as a social goal of utmost importance for institutions and individuals responsible for its completion. It is also a challenge for decision makers in the public health sector in Poland, who should bear in mind that the treatment of diseases of affluence, particularly hypokinetic diseases, being the main cause of premature deaths, is several times more expensive than their prevention. Rational physical activity is nowadays its irreplaceable element. 


\section{Conclusions}

1. The level of physical activity of the observed group of older adults was insufficient in light of the health benefit criteria: over $72 \%$ women and $59 \%$ men did not perform physical activity ensuring health benefits throughout a week. The main reason for not meeting the criteria of physical activity for health benefits was insufficient frequency of moderate- and vigorous-intensity physical activity per week, both among women and men.

2. Promoting physical activity beneficial for health, particularly among older adults aged 50 years and above, is becoming a challenge for public health sector specialists in highly developed societies. Actions taken in this field must be based on a thorough diagnosis of health-oriented behaviors of various social groups, particularly of the role of rational physical activity.

Conflict of interest Władysław Mynarski, Michał Rozpara, Agnieszka Nawrocka, Zbigniew Borek, Aneta Powerska, and Wiesław Garbaciak declare that they have no conflict of interest.

Ethical statements The study was approved by the ethics committee of the University of Physical Education in Katowice (NR 20/2007). All procedures followed were in accordance with the ethical standards of the responsible committee on human experimentation (institutional and national) and with the Helsinki Declaration of 1975, as revised in 2000 (5). Informed consent was obtained from all patients for being included in the study.

\section{References}

1. Becker S, Zimmermann-Stenzel M (2009) No sports = no exercise? Sports, overweight and physical activity in the 5070 age group in Baden-Wurttemberg. J Gerontol Geriatr 42(1): 20-27

2. Biernat E (2011) Aktywność fizyczna mieszkańców Warszawy na przykładzie wybranych grup zawodowych. SGH, Warszawa

3. Biernat E, Stupnicki R, Lebiedziński B, Janczewska L (2008) Assessment of physical activity by applying IPAQ questionnaire. Wychow Fiz Sport 52(2):83-89

4. Brown DR, Yore MM, Ham SA, Macera CA (2005) Physical activity among adults $>$ or $=50$ year with and without disabilities, BRFSS 2001. Med Sci Sports Exerc 37(4):620-629

5. Byberg L, Melhus H, Gedeborg R, Sundstrom J, Ahlbom A, Zethelius B et al (2009) Total mortality after changes in leisure time physical activity in 50 year old men: 35 year follow-up of populationbased cohort. Br J Sports Med 439(7):482

6. Craig CL, Marshall AL, Sjöström M, Bauman AE, Booth ML, Ainsworth BE et al (2003) International physical activity questionnaire: 12 -country reliability and validity. Med Sci Sports Exerc 35(8): $1381-1395$

7. De Jonge L, Nguyen T, Smith SR, Zachwieja JJ, Roy HJ, Bray GA (2001) Prediction of energy expenditure in a whole body indirect calorimeter at both low and high levels of physical activity. Int J Obes Relat Metab Disord 25(7):929-934
8. Drygas W, Bielecki W, Puska P (2002) Assessment of physical activity of populations of 6 European countries under the "Bridging East-West health gap" project. Pol J Sport Med 18(5):169-174

9. Drygas W, Kwaśniewska M, Szcześniewska D, Kozakiewicz K, Głuszek J, Wiercińska E et al (2005) Ocena poziomu aktywności fizycznej dorosłej populacji Polski. Wyniki Programu WOBASZ. Kardiol Pol 63(4):636-640

10. Florindo AA, Latorre Mdo R, Jaime PC, Tanaka T, Zerbini CA (2004) Methodology to evaluation the habitual physical activity in men aged 50 years or more. Rev Saude Publica 38(2):307-314

11. Global recommendations on physical activity for health. Geneva, WHO, 2010. http://www.who.int/dietphysicalactivity/factsheet recommendations/en/index.html (accessed: 2013.01.01)

12. Guedes DP, Goncalves LA (2007) Impact of the habitual physical activity on lipid profile in adults. Arq Bras Endocrinol Metabol 51(1): $72-78$

13. Hallal PC, Victora CG (2004) Reliability and validity of the international physical activity questionnaire (IPAQ). Med Sci Sports Exerc 36:556

14. Haskell WL, Lee IM, Pate RR, Powell KE, Blair SN, Franklin BA et al (2007) Physical activity and public health: updated recommendation for adults from the American College of Sports Medicine and the American Heart Association. Med Sci Sports Exerc 39(8):14231434

15. Haugen HA, Chan LN, Li F (2007) Indirect calorimetry: a practical guide for clinicians. Nutr Clin Pract 22(4):377-388

16. Hoffmann K, Bryl W, Marcinkowski JT, Stróżyńska A, PupekMusialik D (2011) Estimation of physical activity and prevalence of excessive body mass in rural and urban Polish adolescents. Ann Agric Environ Med 18(2):398-403

17. Hopping BN, Erber E, Mead E, Roache C, Sharma S (2010) High levels of physical activity and obesity co-exist amongst Inuit adults in Arctic Canada. J Hum Nutr Diet 23(Suppl 1):110-114

18. http://www.ipaq.ki.se/ipaq.htm (accessed: 2013.01.01)

19. Hughes JP, McDowell MA, Brody DJ (2008) Leisure-time physical activity among US adults 60 or more years of age: results from NHANES 1999-2004. J Phys Act Health 5(3):347-358

20. Hurtig-Wennlof A, Hagstromer M, Olsson LA (2010) The international physical activity questionnaire modified for the elderly: aspects of validity and feasibility. Public Health Nutr 13(11):1847-1854

21. Huy C, Schneider S (2008) Instrument for the assessment of middle-aged and older adults' physical activity: design, reliability and application of the German-PAQ-50+. J Gerontol Geriatr 41(3):208-216

22. Jurakic D, Pedisic Z, Andrijasevic M (2009) Physical activity of Croatian population: cross-sectional study using international physical activity questionnaire. Croat Med J 50(2):165-173

23. Meyer K, Rezny L, Breuer C, Lamprecht M, Stamm HP (2005) Physical activity of adults aged 50 years and older in Switzerland. Soz Praventivmed 50(4):218-229

24. Nawrocka A, Prończuk A, Mynarski W, Garbaciak W (2012) Physical activity of top level managers in the context of the public health recommendations. Med Pr 63(3):271-279

25. Puciato D (2008) Ekonomiczne uwarunkowania podejmowania aktywności ruchowej w czasie wolnym. In: Siwiński W, Tauber R, Mucha-Szajek E (eds) Współczesne tendencje w rekreacji i turystyce. WSHiG, Poznań, pp 409-414

26. Rahl RL (2010) Physical activity and health guidelines: recommendations for various ages fitness levels, and conditions from 57 authoritative sources. Human Kinetics, Champaign

27. Rozpara M, Mynarski W, Czapla K (2008) Szacowanie kosztu energetycznego aktywności fizycznej na podstawie badań kwestionariuszem IPAQ. In: Mynarski W (ed) Teoretyczne i empiryczne zagadnienia rekreacji i turystyki. AWF, Katowice, pp $257-281$ 
28. Rütten A, Vuillemin A, Ooijendijk WTM, Schena F, Sjöström M, Stahl T et al (2003) Physical activity monitoring in Europe. The European Physical Activity Surveillance System (EUPASS) approach and indicator testing. Public Health Nutr 6:377-384

29. Schnohr P, Lange P, Scharling H, Jensen SJ (2006) Long-term physical activity in leisure time and mortality from coronary heart disease, stroke, respiratory diseases and cancer. The Copenhagen City heart study. Eur J Cardiovasc Prev Rehabil 13:173-179

30. Sjöström M, Oja P, Hagstromer M, Smith B, Bauman A (2006) Health-enhancing physical activity across European Union countries: the eurobarometer study. J Public Health 14:291-300
31. Suchomel A, Sigmundová D, Frömel K (2008) The lifestyle of the inhabitants of the Liberec region. Hum Mov 9(1):19 26

32. Tomioka K, Iwamoto J, Saeki K, Okamoto N (2011) Reliability and validity of the international physical activity questionnaire (IPAQ) in elderly adults: the Fujiwarakyo study. J Epidemiol 21(6):459-465

33. Vanhees L, Lefevre J, Philippaerts R, Martens M, Huygens W, Troosters $\mathrm{T}$ et al (2005) How to assess physical activity? How to assess physical fitness? Eur J Cardiovasc Prev Rehabil 12(2): $102-114$ 